\title{
An Open-Label Crossover Study of the Pharmacokinetics of the 60-mg Edoxaban Tablet Crushed and Administered Either by a Nasogastric Tube or in Apple Puree in Healthy Adults
}

\author{
Kenneth Duchin $^{1}$ - Anil Duggal ${ }^{1}$ - George J. Atiee ${ }^{1}$ - Motonori Kidokoro' ${ }^{1}$. \\ Tadanobu Takatani ${ }^{1} \cdot$ Nicole Lazarus Shipitofsky $^{1} \cdot$ Ling He $^{1} \cdot$ George Zhang $^{1}$. \\ Tarundeep Kakkar ${ }^{1}$
}

Published online: 17 May 2017

(c) The Author(s) 2017. This article is an open access publication

\begin{abstract}
Background Edoxaban is an orally active, direct factor Xa inhibitor indicated to reduce the risk of stroke and systemic embolism in non-valvular atrial fibrillation and for the treatment of venous thromboembolism.

Objectives This study assessed the pharmacokinetics, safety, and tolerability of the edoxaban 60-mg tablet crushed and administered via a nasogastric tube in a water suspension or orally mixed in apple puree.

Methods This phase 1, open-label, crossover study randomized 30 healthy adults to receive three edoxaban treatment regimens (oral 60-mg edoxaban tablet, or 60-mg edoxaban tablet crushed and administered via a nasogastric tube or orally in apple puree) in one of six treatment sequences.

Results Total edoxaban exposure was similar between the intact and crushed tablet regimens (mean area under the plasma concentration-time curve from time zero to infinity: whole tablet, $2132 \mathrm{ng} \cdot \mathrm{h} / \mathrm{mL}$; nasogastric tube, $2021 \mathrm{ng} \cdot \mathrm{h} / \mathrm{mL}$; apple puree, $2076 \mathrm{ng} \cdot \mathrm{h} / \mathrm{mL}$ ). Mean maximum plasma concentration, area under the plasma concentration-time curve from time zero to the time of the last measurable concentration, terminal half-life, and apparent total body clearance values were also similar. Time to maximum plasma concentration was significantly shorter for the nasogastric tube suspension and apple puree vs. the whole tablet [Hodges-Lehmann estimate of median difference (90\% confidence interval): $-0.75(-1.25,-0.28)$; $p=0.0003$ and $-0.62(-0.99,-0.26) ; p=0.0024$, respectively]. The maximum plasma concentation, area
\end{abstract}

Tarundeep Kakkar

tkakkar@dsi.com

1 Daiichi Sankyo Pharma Development, 399 Thornall Street, Edison, NJ 08837, USA under the plasma concentration-time curve from time zero to infinity, and area under the plasma concentration-time curve from time zero to the time of the last measurable concentration were similar between treatment regimens; $90 \%$ confidence interval of the geometric least-squares means ratios were within the predefined $80-125 \%$ bioequivalence criterion. The safety and tolerability of edoxaban did not differ between treatment regimens.

Conclusion The results support the use of edoxaban tablets crushed and administered either via a nasogastric tube or orally mixed in apple puree in patients who are unable to swallow solid oral dose formulations.

\section{Key Points}

Edoxaban is a direct oral anticoagulant that has been approved in North America, Europe, and Asia for the reduction of stroke risk in non-valvular atrial fibrillation and the treatment of venous thromboembolism.

Dysphagia (difficulty swallowing) is a major concern in the elderly population and may result in reduced patient adherence to medications. Therefore, solid oral formulations crushed and mixed into food or provided as a water suspension via a nasogastric tube are important alternative methods of administration.

This randomized single-dose crossover study supports the use of 60-mg edoxaban tablets crushed and administered either in apple puree and taken orally or as a water suspension via a nasogastric tube as alternative methods of edoxaban administration in healthy adults. 


\section{Introduction}

Edoxaban is an orally active, direct factor Xa inhibitor with linear and predictable pharmacokinetics approved in North America, Europe, and Asia for the reduction of stroke risk in non-valvular atrial fibrillation (NVAF) and the treatment of venous thromboembolism (VTE). The recommended edoxaban dose is $60 \mathrm{mg}$ for patients with NVAF or VTE not meeting the dose reduction criteria, and $30 \mathrm{mg}$ for patients meeting the dose reduction criteria (i.e., creatinine clearance $15-50 \mathrm{~mL} / \mathrm{min}$ for NVAF, or creatinine clearance $15-50 \mathrm{~mL} / \mathrm{min}$, body weight $\leq 60 \mathrm{~kg}$, or taking select concomitant P-glycoprotein inhibitors for VTE) [1]. The absolute bioavailability of oral edoxaban $60 \mathrm{mg}$ in healthy subjects is $62 \%$ [2] and is not significantly affected by food [3]. Edoxaban is rapidly absorbed, primarily in the proximal small intestine in healthy subjects [4], with peak plasma concentrations occuring within $1-2 \mathrm{~h}$ after dosing [5]. The terminal elimination half-life of edoxaban in plasma following oral administration has a range of 10-14 h [1]. Edoxaban is eliminated through multiple pathways, including renal and biliary excretion and metabolism. Renal clearance accounts for approximately 50\% of total clearance and metabolism and biliary secretion account for the remaining 50\% [6].

Elderly or terminally ill patients with dysphagia often have difficulty swallowing solid oral medications [7]. Dysphagia is a major concern in the elderly population [8] and may result in reduced patient adherence to medications $[9,10]$. Therefore, solid oral formulations crushed and mixed into food or provided as a water suspension via a nasogastric (NG) tube are important alternative methods of administration [11]. However, these manipulations may alter the bioavailability of a drug. Consequently, assessments of alternative methods of administration, with respect to bioavailability and pharmacokinetic (PK) properties, are necessary. The primary objective of this study was to assess the PK, safety, and tolerability profiles of the edoxaban 60-mg tablet in healthy adults when crushed and administered either via a NG tube or mixed with apple puree and ingested.

\section{Methods}

\subsection{Study Design}

This was a phase 1, single-clinical unit, open-label, randomized, single-dose, three-period, three-treatment crossover study of single-dose edoxaban conducted in USA from 26 April to 13 May, 2016. The primary objective of this study was to evaluate the bioavailability of edoxaban 60-mg tablets crushed and delivered either as a suspension via a NG tube or as a mixture with apple puree and ingested relative to edoxaban whole tablets in healthy adults. The secondary objectives were to assess the safety and tolerability of edoxaban tablets crushed and delivered either via a NG tube as a suspension or mixed with apple puree and ingested, and to assess the PK properties of the most abundant active metabolite of edoxaban, M-4, for all treatments. A single 60-mg dose of edoxaban represents the highest dose approved for its indications (i.e., NVAF and VTE) [1], and was, therefore, selected for use in this study. Prior to the initiation of the clinical study, in vitro studies were conducted and demonstrated the lack of adsorption of drug in suspension by the NG tube in the concentrations used in this study. In addition, edoxaban suspension was stable for $4 \mathrm{~h}$ in aqeous media, as well as in apple puree (data on file).

At screening and at check-in (day -1), participants were admitted to the clinical facility (Worldwide Clinical Trials, San Antonio, TX, USA) and were evaluated for inclusion/ exclusion criteria, underwent a physical examination, provided blood and urine samples for clinical laboratory testing, and had vital signs checked. All participants remained in the clinical unit through the duration of the study (18 days). On day 1, eligible volunteers were randomized to receive three treatments (A: single oral 60-mg edoxaban tablet with water; B: single 60-mg edoxaban crushed tablet via a NG tube; C: single 60-mg edoxaban crushed tablet mixed in apple puree; Table 1) in one of six treatment sequences (i.e., $\mathrm{ABC}, \mathrm{ACB}, \mathrm{BAC}, \mathrm{BCA}, \mathrm{CAB}$, or $\mathrm{CBA}$ ). All treatments were administered in the morning following an overnight fast of $10 \mathrm{~h}$. Treatments were administered on day 1 (treatment period 1), day 8 (treatment period 2), and day 15 (treatment period 3). Each treatment period was separated by a washout period of 7 days.

The NG tube used in this study was composed of polyvinyl chloride, and the lumen size was 12 French and was 48 inches in length (CR Bard, St. Louis, MO, USA). The study complied with local regulations, the Declaration of Helsinki, and the International Conference on Harmonisation Guidelines on Good Clinical Practice. All subjects provided written informed consent before participation.

\subsection{Study Population}

Healthy participants, determined by medical history, physical examinations, vital signs, 12-lead electrocardiograms, and clinical laboratory tests, were eligible to enroll if they were between 18 and 60 years of age, with a body mass index of $18-30 \mathrm{~kg} / \mathrm{m}^{2}$ at screening. Women of childbearing potential had to have a negative serum pregnancy test before each dose of study drug. Women of nonchildbearing potential had to be surgically sterile or 
Table 1 Study treatments

\begin{tabular}{|c|c|}
\hline $\begin{array}{r}\text { Treatment A } \\
\text { (reference) }\end{array}$ & Single oral dose of a $60-\mathrm{mg}$ round tablet of edoxaban with $240 \mathrm{~mL}$ of water \\
\hline Treatment B & $\begin{array}{l}\text { Single oral dose of a } 60-\mathrm{mg} \text { tablet of edoxaban was crushed and mixed with } 75 \mathrm{~mL} \text { of water followed by } 3 \times 55-\mathrm{mL} \\
\text { water rinses of a mortar and pestle, and administered via a NG tube as a suspension. Care was taken to assure that no } \\
\text { visible residue was left on the mortar and pestle. Prior to drug administration, the position of the NG tube was confirmed } \\
\text { with an X-ray, and } 20 \mathrm{~mL} \text { of water was injected into the tube to pre-wet and prime the lumen. Insertion of the NG tube } \\
\text { was performed within } 30-60 \mathrm{~min} \text { of administration of the study drug and remained in place for at least } 5 \mathrm{~min} \text { after the } \\
\text { last water rinse. After the study drug suspension had been administered, the NG tube was flushed with } 15-30 \mathrm{~mL} \text { of } \\
\text { water }\end{array}$ \\
\hline Treatment $\mathrm{C}$ & $\begin{array}{l}\text { Single dose of a } 60-\mathrm{mg} \text { tablet of edoxaban was crushed and mixed with } 40 \mathrm{~g} \text { of apple puree }\left(\text { Gerber }{ }^{\circledR} \text {, Organic } 1 \mathrm{st}\right. \\
\text { Foods }{ }^{\circledR} \text {, apple) followed by } 3 \times 80 \text {-mL water rinses of the mortar and pestle, and ingested. Care was taken to assure } \\
\text { that no visible residue was left on the mortar and pestle }\end{array}$ \\
\hline
\end{tabular}

$N G$ nasogastric

naturally postmenopausal for at least 24 months prior to starting the study drug. Exclusion criteria included a history of major bleeding, trauma, or surgical procedure within 6 months of the first dose; malignancy in the past 5 years; and coagulation disorders or other conditions and medications that could affect the absorption and/or excretion of the study drug.

The main covariates affecting the pharmacokinetics of edoxaban are renal function and body weight [6]. After accounting for these covariates, intrinsic factors such as age, sex, and race do not affect the pharmacokinetics of edoxaban. The crossover study design of this trial controlled these factors because the study was an intra-subject comparison of the pharmacokinetics of edoxaban, and subjects were kept in the clinical unit for the entire study.

\subsection{Sample Collection and Analysis of Plasma Edoxaban}

Blood samples were collected in prechilled, lithium heparin blood collection tubes. On the day of treatment (i.e., days 1,8 , and 15), blood samples were collected predose (0) and at $0.5,1,1.5,2,2.5,3,4,6,8,10$, and $12 \mathrm{~h}$ postdose. Over the following 3 days, blood samples were collected at 24, 36, 48, 60, and $72 \mathrm{~h}$ post-dose.

Plasma samples were stored at a nominal temperature of $-20^{\circ} \mathrm{C}$. Plasma concentrations of free-base edoxaban and M-4 were measured at $Q^{2}$ Solutions (Ithaca, NY, USA) using a validated liquid chromatography-tandem mass spectrometry method, similar to what has previously been reported [12]. The calibration curves for edoxaban and M-4 had a range of 0.764-382 and 0.0792-7.92 ng/mL, respectively. Sample preparation was conducted using Tomtec Quadra 96 Sample Processor. Edoxaban, M-4, and respective deuterium-labeled internal standards (d6-edoxaban and d3-M4) were isolated from plasma samples (200 $\mu \mathrm{L})$ using an Oasis MCX (mixed-mode ion exchange resin) (Waters, Milford, MA, USA), 96-well solid-phase extraction plate. Extracted plasma samples were injected into gradient chromatography (ZORBAX Eclipse XDB Phenyl, Agilent Technologies, Santa Clara, CA, USA [50-mm length, 2.1-mm internal diameter, 5- $\mu \mathrm{m}$ particle size]) at a flow rate of $0.3 \mathrm{~mL} / \mathrm{min}$, using $5 \mathrm{mM}$ ammonium acetate ( $\mathrm{pH}$ 7.0) as mobile phase $\mathrm{A}$, and methanol as mobile phase B. The eluted analytes and internal standards were detected by a mass spectrometer (SCIEX API 4000 triple quadrupole with TurboIonSpray source, SCIEX, Framingham, MA, USA) in positive ionization mode. The parent $\rightarrow$ daughter ion transitions, monitored for edoxaban and its internal standards, were $\mathrm{m} / \mathrm{z} 550.4 \rightarrow 366.3$ and $\mathrm{m} / \mathrm{z} 556.4 \rightarrow 372.3$, respectively; the transitions for $M-4$ and its internal standards were $\mathrm{m} / \mathrm{z} 521.4 \rightarrow 339.3$ and $\mathrm{m} / \mathrm{z}$ $524.4 \rightarrow 342.3$, respectively. Assay validation demonstrated that, for edoxaban, the intra- and inter-assay precision (coefficient of variation) values were within 11.0 and $8.8 \%$, respectively; the intra- and inter-assay accuracy values were within \pm 6.9 and $\pm 3.8 \%$, respectively. For M-4, the intra- and inter-assay precision (coefficient of variation) values were within 12.3 and $11.5 \%$, respectively; the intra- and inter-assay accuracy values were within \pm 18.5 and $\pm 8.8 \%$, respectively.

\subsection{Pharmacokinetic Assessments}

Pharmacokinetic parameters for edoxaban and M-4 were calculated using Phoenix ${ }^{\mathrm{TM}}$ WinNonlin ${ }^{\circledR}$ Professional (Certara, Princeton, NJ, USA). These included area under the plasma concentration-time curve (AUC) from time zero to the time of the last measurable concentration $\left(\mathrm{AUC}_{\text {last }}\right)$, AUC from time zero to infinity $\left(\mathrm{AUC}_{\infty}\right)$, maximum plasma concentration $\left(C_{\max }\right)$, time to maximum plasma concentration $\left(T_{\max }\right)$, terminal half-life, and apparent total body clearance.

\subsection{Safety and Tolerability Assessments}

Adverse events (AEs) were monitored up to 30 days after the last dose of study medication, and were coded using the 
Medical Dictionary for Regulatory Activities coding dictionary.

\subsection{Planned Sample Size and Statistical Analysis}

A total of 30 participants, five per treatment sequence, was planned for enrollment, with the expectation that 24 participants would complete the study. The sample size was not based on statistical power considerations; a planned sample size of 24 participants was selected because it is a typically robust subject number for a crossover study.

All PK parameters were calculated using the PK analysis set, which included all participants with no major deviations from treatment intake (e.g., vomiting) for whom the primary PK data were considered sufficient and interpretable. The edoxaban and M-4 concentrations across scheduled times are presented using descriptive statistics by treatment. $\mathrm{AUC}_{\text {last }}, \mathrm{AUC}_{\infty}$, and $C_{\max }$ for treatments $\mathrm{B}$ (NG tube) and $\mathrm{C}$ (apple puree) were compared with the reference treatment A (oral tablet) using a mixed-effect analysis of variance on the $\ln$-transformed PK values with sequence, treatment, and period as fixed effects, and subject nested within sequence as a random effect. The resulting geometric least-squares means (LSM) and LSM ratios $\pm 90 \%$ confidence intervals (CIs) are presented. Time to maximum plasma concentration comparisons were conducted using the Wilcoxon signed-rank test and the Hodges-Lehmann estimate of median difference. All statistical analyses were conducted using SAS Version 9.3 (SAS Inc., Cary, NC, USA).

\section{Results}

\subsection{Demographics and Baseline Clinical Characteristics}

All randomized participants $(n=30)$ received at least two doses of the study drug; 30 participants were included in the PK analysis set. One participant was discontinued from the study after treatment period 2 and did not receive reference treatment A (oral tablet) because it was discovered that he was a participant in another clinical study. The majority of participants were male, $50 \%$ were White, and the mean \pm standard deviation age was $40.3 \pm 11.0$ years (Table 2).

\subsection{Pharmacokinetic Properties}

In general, the mean plasma concentrations of edoxaban over time were similar for all three treatments (Fig. 1a, b). However, the mean peak concentration occurred earlier for
Table 2 Subject demographics and baseline characteristics

\begin{tabular}{lc}
\hline Characteristics & Overall $(n=30)$ \\
\hline Age (years) & $15(50.0)$ \\
$18-39, n(\%)$ & $15(50.0)$ \\
$40-60, n(\%)$ & $40.3(11.0)$ \\
Mean (SD) & \\
Sex, $n(\%)$ & $17(56.7)$ \\
Male & $13(43.3)$ \\
Female & $15(50.0)$ \\
Race, $n(\%)$ & $13(43.3)$ \\
White & $2(6.6)$ \\
Black & \\
Other & $26.3(2.6)$ \\
BMI $\left(\mathrm{kg} / \mathrm{m}^{2}\right)$ & \\
Mean $(\mathrm{SD})$ & \\
\hline
\end{tabular}

$B M I$ body mass index, $S D$ standard deviation

the tablet crushed and adminstered either via a NG tube or mixed in apple puree relative to the intact tablet (inset Fig. 1a).

A summary of the PK parameters of edoxaban is shown in Table 3. The total exposure of edoxaban was similar between the whole tablet and crushed tablet formulations, with mean $\mathrm{AUC}_{\infty}$ values of 2132, 2021, and $2076 \mathrm{ng} \cdot \mathrm{h} / \mathrm{mL}$ for the whole tablet, suspension administered via a NG tube, and mixture with apple puree, respectively. Mean $C_{\text {max }}, \mathrm{AUC}_{\text {last }}$, terminal half-life, and apparent total body clearance values were also similar between the whole tablet and oral suspension formulations. Time to maximum plasma concentration was significantly shorter by $0.5 \mathrm{~h}$ for the NG route and when mixed in apple puree vs. the intact tablet [Hodges-Lehmann estimate of median difference $(90 \% \mathrm{CI}):-0.75(-1.25,-0.28) ; p=0.0003$ and -0.62 $(-0.99,-0.26) ; p=0.0024$, respectively]. However, the $C_{\max }, \mathrm{AUC}_{\infty}$, and $\mathrm{AUC}_{\text {last }}$ values for all three treatment regimens were similar, with $90 \%$ CIs of the geometric LSM ratios falling within the predefined $80-125 \%$ bioequivalence criterion stipulated by regulatory agencies (Table 4). The mean concentration-time profiles for the edoxaban metabolite M-4 were also similar for all three treatments (Fig. 2a, b). A summary of the PK parameters of M-4 is shown in Table 5. M-4 mean $C_{\max }, \mathrm{AUC}_{\infty}, \mathrm{AUC}_{\text {last }}$, and terminal half-life values were similar when edoxaban was administered as a whole tablet or as a crushed tablet via a NG tube or mixed with apple puree; median $T_{\max }$ was $2.0 \mathrm{~h}$ for the whole tablet and $1.5 \mathrm{~h}$ for the crushed tablet formulations. The mean metabolite-to-parent ratios for M-4 were $8.6,8.3$, and $8.4 \%$ for the whole tablet, crushed suspension administered via a NG tube, and mixed with apple puree, respectively. 
Fig. 1 Plasma edoxaban concentration-time profiles following administration of a single, oral 60-mg edoxaban tablet with water (Treatment A), a 60-mg edoxaban tablet crushed and given as a suspension via a nasogastric tube (Treatment B), or a $60-\mathrm{mg}$ edoxaban tablet crushed and given orally mixed with apple puree (Treatment C). a Mean plasma edoxaban concentration-time profiles. b Semi-logarithmic mean plasma edoxaban concentration-time profiles. Inset Concentration-time profiles for the first $10 \mathrm{~h}$ only. Error bars represent the standard deviation
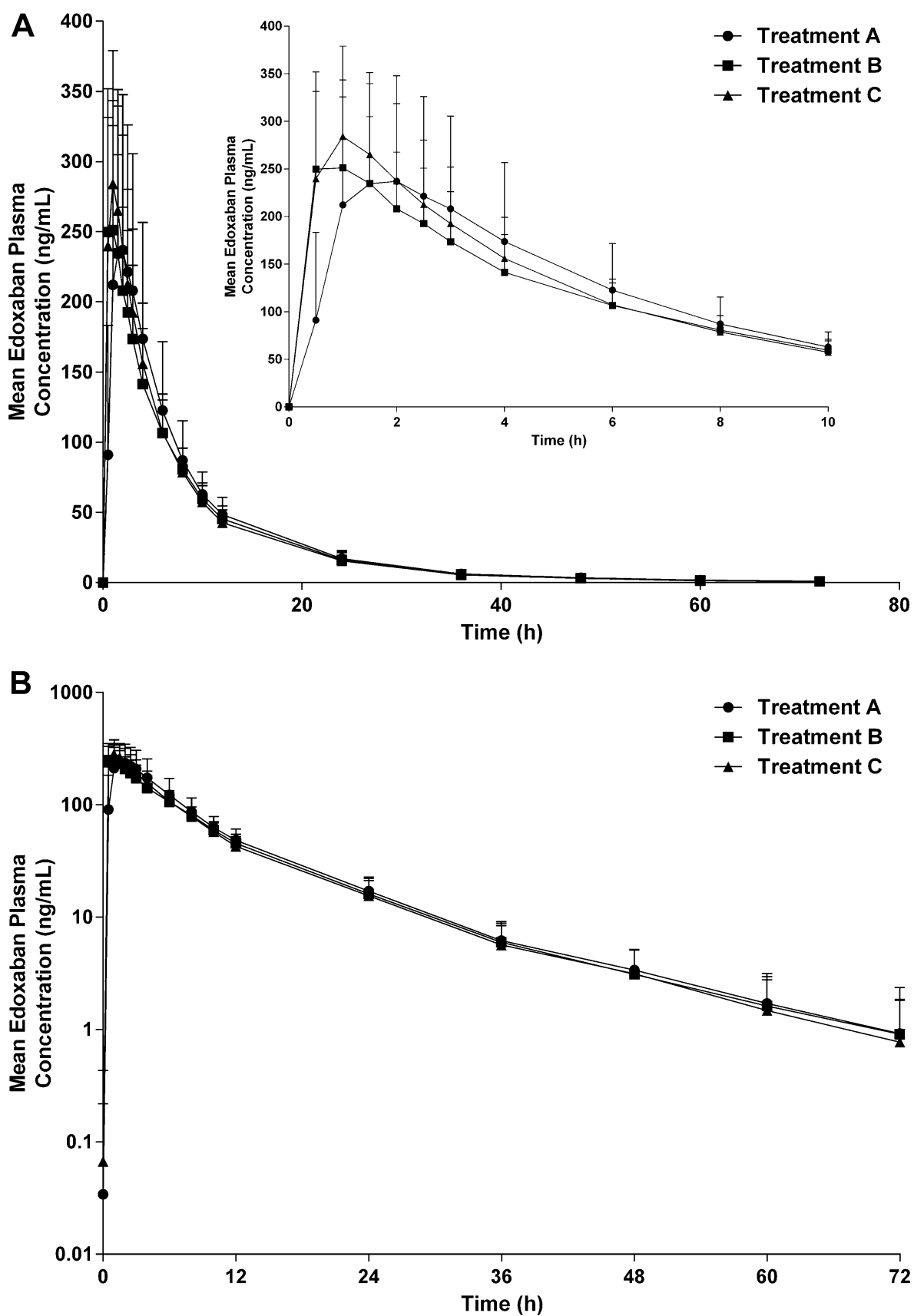

\subsection{Safety and Tolerability}

There were no clinically significant changes in physical examinations, clinical laboratory test results, vital signs, or ECGs attributable to edoxaban. All treatment-emergent AEs reported were of mild intensity, self-limited, did not require any medical therapy, and resolved without any sequelae. Of the treatment-emergent AEs that were related to study drug, one subject developed vaginal hemorrhage and another had conjunctival hemorrhage after receiving edoxaban via a NG tube or with apple puree, respectively. Other treatment-emergent AEs during the study included neutropenia $(n=2)$, constipation $(n=2)$, facial pain $(n=1)$, vessel puncture-site pain $(n=1)$, laceration $(n=1)$, muscle spasm $(n=1)$, menstruation irregularity $(n=1)$, dysphonia $(n=1)$, nasal congestion $(n=1)$, oropharyngeal discomfort $(n=1)$, and rhinorrhea $(n=1)$.

\section{Discussion}

The results of this study conclude that the administration of a 60-mg edoxaban tablet that is crushed and given either via a NG tube in a water suspension or orally mixed with 
Table 3 Summary of plasma pharmacokinetic parameters of edoxaban

\begin{tabular}{lllllll}
\hline Treatment $(n=30)$ & $C_{\max }{ }^{\mathrm{a}}(\mathrm{ng} / \mathrm{mL})$ & $\mathrm{AUC}_{\infty}{ }^{\mathrm{a}}(\mathrm{ng} \cdot \mathrm{h} / \mathrm{mL})$ & $\mathrm{AUC}_{\text {last }}{ }^{\mathrm{a}}(\mathrm{ng} \cdot \mathrm{h} / \mathrm{mL})$ & $T_{\max }^{\mathrm{b}}(\mathrm{h})$ & $t_{1 / 2}{ }^{\mathrm{a}}(\mathrm{h})$ & $\mathrm{CL} / F^{\mathrm{a}}(\mathrm{L} / \mathrm{h})$ \\
\hline Treatment A & $293(107)^{\mathrm{c}}$ & $2132(547)^{\mathrm{d}}$ & $2089(548)^{\mathrm{c}}$ & $1.5(0.5-8.0)^{\mathrm{c}}$ & $11.5(3.3)^{\mathrm{d}}$ & $30.1(8.0)^{\mathrm{d}}$ \\
Treatment B & $283(95)$ & $2021(423)$ & $1993(413)$ & $1.0(0.5-3.0)$ & $10.8(3.7)$ & $31.0(6.5)$ \\
Treatment C & $303(96)$ & $2076(453)$ & $2051(451)$ & $1.0(0.5-1.5)$ & $10.9(3.3)$ & $30.2(6.3)$ \\
\hline
\end{tabular}

$A U C_{\infty}$ area under the plasma concentration-time curve from time zero to infinity, $A U C_{\text {last }}$ area under the plasma concentration-time curve from time zero to the time of the last measurable observation, $C L / F$ apparent total body clearance, $C_{\max }$ maximum plasma concentration, $t_{1 / 2}$ terminal half-life, $T_{\max }$ time to maximum plasma concentration

${ }^{a}$ Arithmetic mean (standard deviation) unless indicated otherwise

b Median (range)

c $n=29$

d $n=28$

Treatment $\mathrm{A}=$ single oral dose of an intact $60-\mathrm{mg}$ edoxaban tablet with water; Treatment $\mathrm{B}=$ single dose of a 60 -mg edoxaban tablet crushed and suspended in water and administered via a nasogastric tube; Treatment $\mathrm{C}=$ single oral dose of a 60-mg edoxaban tablet crushed and given orally mixed with apple puree and ingested

Table 4 Statistical analysis of the pharmacokinetic parameters of edoxaban

\begin{tabular}{|c|c|c|c|c|c|c|}
\hline $\begin{array}{l}\text { Treatment } \\
(n=30)\end{array}$ & $C_{\max }^{\mathrm{a}}(\mathrm{ng} / \mathrm{mL})$ & $\begin{array}{l}\mathrm{AUC}_{\infty}{ }^{\mathrm{a}}(\mathrm{ng} \cdot \mathrm{h} / \\
\mathrm{mL})\end{array}$ & $\begin{array}{l}\mathrm{AUC}_{\text {last }}{ }^{\mathrm{a}}(\mathrm{ng} \cdot \mathrm{h} / \\
\mathrm{mL})\end{array}$ & Ratio $C_{\max }{ }^{\mathrm{b}}(\%)$ & Ratio $\mathrm{AUC}_{\infty}{ }^{\mathrm{b}}(\%)$ & Ratio $\mathrm{AUC}_{\text {last }} \mathrm{b}(\%)$ \\
\hline Treatment A & 265.4 & 2064.2 & 2019.3 & & & \\
\hline Treatment B & 267.6 & 1978.8 & 1952.2 & $100.8(91.2-111.4)$ & $95.9(92.1-99.8)$ & 96.7 (92.7-100.9) \\
\hline Treatment $\mathrm{C}$ & 288.2 & 2031.0 & 2006.0 & $108.6(98.3-120.0)$ & $98.4(94.5-102.4)$ & 99.3 (95.2-103.7) \\
\hline
\end{tabular}

$A U C_{\infty}$ area under the plasma concentration-time curve from time zero to time infinity, $A U C_{\text {last }}$ area under the plasma concentration-time curve from time zero to the time of the last measurable observation, $C_{\max }$ maximum plasma concentration

a Geometric least-squares mean

${ }^{\text {b }}$ Geometric least-squares mean ratio vs. reference (90\% confidence interval)

Treatment $\mathrm{A}=$ single oral dose of an intact $60-\mathrm{mg}$ edoxaban tablet with water; Treatment $\mathrm{B}=$ single dose of a 60 -mg edoxaban tablet crushed and suspended in water and administered via a nasogastric tube; Treatment $\mathrm{C}=$ single oral dose of a 60 -mg edoxaban tablet crushed and given orally mixed with apple puree and ingested

apple puree does not impact the extent of edoxaban absorption relative to an intact tablet. The $C_{\max }$ and $\mathrm{AUC}$ geometric LSM ratios for crushed tablet formulations were bioequivalent with the whole uncrushed tablet, according to the predefined $80-125 \%$ bioequivalence criterion. These results are consistent with the results of a previous food effect study, which concluded that food does not have a clinically significant effect on the bioavailability of edoxaban [3]. Furthermore, an edoxaban tablet crushed and administered either via a NG tube or with apple puree displays similar total exposure, and metabolite-to-parent ratios for the main active metabolite of edoxaban, M-4, compared with a whole tablet administered orally, suggesting that the biotransformation of edoxaban is not affected by the mode of drug administration.

Solid oral formulations crushed and mixed in food or provided as a water suspension via a NG tube represent viable alternative methods of administration for patients who have difficulty swallowing [11]. Based on the results of studies on alternative methods of administration of nonvitamin $\mathrm{K}$ oral anticoagulants conducted to date, crushed apixaban and rivaroxaban tablets are well tolerated when administered either with food or via a NG tube. Specifically, when rivaroxaban 20-mg or apixaban 5-mg crushed tablets were administered as suspensions via a NG tube, mean exposure decreased by only $5-11 \%$ [AUC $\infty(90 \%$ CI); 0.89 (0.86-0.92) and 0.95 (0.91-1.00), respectively] [13, 14]. Furthermore, while $C_{\max }$ for the rivaroxaban 20-mg crushed tablet administered as a suspension via a NG tube was slightly below the lower bioequivalence limit [0.82 (0.78-0.86)], it was within the bioequivalence limits for the apixaban 5-mg crushed tablet [0.88 (0.83-0.94)]. However, when rivaroxaban 20-mg and apixaban $2 \times 5$ mg crushed tablets were administered as applesauce suspensions, the mean exposure decreased by only $5-16 \%$ [AUC $_{\infty}(90 \% \mathrm{CI}) ; 0.95(0.92-0.98)$ and 0.84 (0.80-0.88), respectively]. Furthermore, while $\mathrm{C}_{\max }$ for the rivaroxaban 20-mg crushed tablet in the applesauce suspension was 
Fig. 2 Plasma M-4

concentration-time profiles following administration of a single, oral 60-mg edoxaban tablet with water (Treatment A), a 60-mg edoxaban tablet crushed and given as a suspension via a nasogastric tube (Treatment B), or a $60-\mathrm{mg}$ edoxaban tablet crushed and given orally mixed with apple puree (Treatment C). a Mean plasma M-4 concentration-time profiles. b Semi-logarithmic mean plasma M-4 concentration-time profiles. Inset Concentration-time profiles for the first $10 \mathrm{~h}$ only. Error bars represent the standard deviation
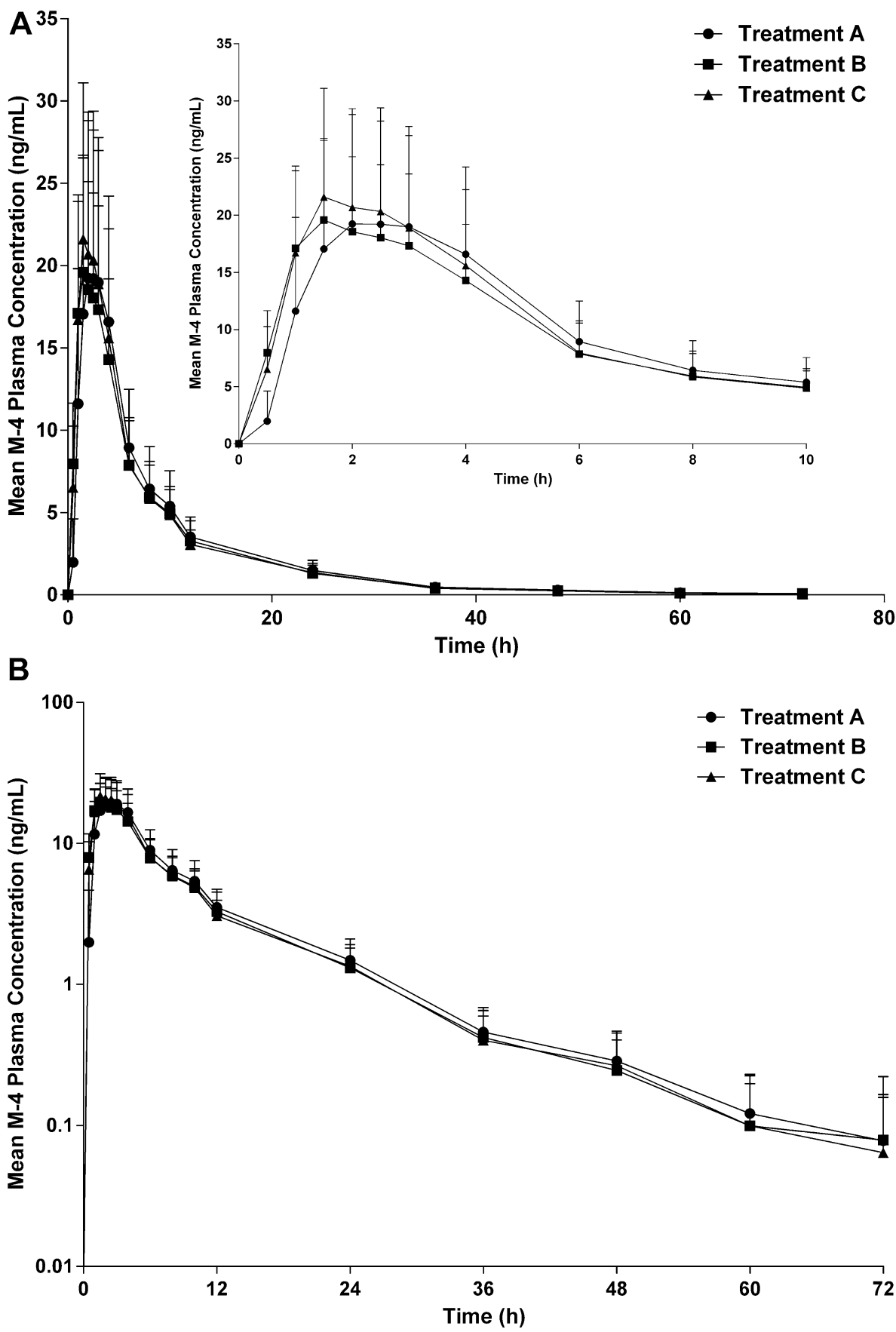

within the bioequivalence limits [0.90 (0.86-0.94)], it was slightly below the lower bioequivalence limit for the apixaban $2 \times 5$-mg crushed tablet in applesauce suspension [0.79 (0.74-0.84)] [13-15].

In vitro studies, conducted prior to the initiation of this study, demonstrated that when edoxaban was given in a water suspension by a NG tube there was no adherence of edoxaban to the tube for edoxaban concentrations used in this study. Furthermore, the edoxaban suspension was stable in aqeous media and in apple puree. However, there are several limitations of this study that could limit its generalizability-the type of NG tube used (polyvinyl chloride), consistency of the apple puree, and the rigor in which the mortar and pestle were cleaned after crushing each tablet.

\section{Conclusions}

Results of this randomized, single-dose, crossover study support the use of edoxaban tablets crushed and administered either in apple puree and taken orally or as a water 
Table 5 Summary of plasma M-4 pharmacokinetic parameters

\begin{tabular}{|c|c|c|c|c|c|c|}
\hline Treatment $(n=30)$ & $C_{\max }^{\mathrm{a}}(\mathrm{ng} / \mathrm{mL})$ & $\operatorname{AUC}_{\infty}{ }^{a}(\mathrm{ng} \cdot \mathrm{h} / \mathrm{mL})$ & $\mathrm{AUC}_{\text {last }}{ }^{\mathrm{a}}(\mathrm{ng} \cdot \mathrm{h} / \mathrm{mL})$ & $T_{\max }^{\mathrm{b}}(\mathrm{h})$ & $t_{1 / 2}^{\mathrm{a}}(\mathrm{h})$ & $\operatorname{MPR}^{\mathrm{a}}(\%)$ \\
\hline Treatment A & $22.0(9.0)^{\mathrm{c}}$ & $169(57)^{\mathrm{d}}$ & $164(56)^{\mathrm{c}}$ & $2.0(1.0-10.0)^{\mathrm{c}}$ & $11.0(3.6)^{\mathrm{d}}$ & $8.6(2.5)^{\mathrm{d}}$ \\
\hline Treatment B & $20.5(7.2)$ & $158(46)^{\mathrm{c}}$ & 157 (46) & $1.5(1.0-3.0)$ & $9.9(3.2)^{\mathrm{c}}$ & $8.3(2.2)^{\mathrm{c}}$ \\
\hline Treatment $\mathrm{C}$ & $22.5(9.9)$ & $166(57)^{\mathrm{c}}$ & $161(56)$ & $1.5(1.0-3.0)$ & $9.9(2.7)^{\mathrm{c}}$ & $8.4(2.4)^{\mathrm{c}}$ \\
\hline
\end{tabular}

$A U C_{\infty}$ area under the plasma concentration-time curve from time zero to infinity, $A U C_{\text {last }}$ area under the plasma concentration-time curve from time zero to the time of the last measurable observation, $C_{\max }$ maximum plasma concentration, $M P R$ metabolite-to-parent ratio, $t_{1 / 2}$ terminal halflife, $T_{\max }$ time to maximum plasma concentration

${ }^{a}$ Arithmetic mean (standard deviation) unless indicated otherwise

b Median (range)

c $n=29$

${ }^{\mathrm{d}} n=27$

Treatment $\mathrm{A}=$ single oral dose of an intact $60-\mathrm{mg}$ edoxaban tablet with water; Treatment $\mathrm{B}=$ single dose of a $60-\mathrm{mg}$ edoxaban tablet crushed and given orally suspended in water and administered via a nasogastric tube; Treatment $\mathrm{C}=$ single oral dose of a 60 -mg edoxaban tablet crushed and mixed with apple puree and ingested

suspension via a NG tube as suitable alternative methods of administration in patients who are unable to swallow solid oral dose formulations of edoxaban. These findings further suggest that these alternate modes of administration are interchangeable with the oral edoxaban tablet swallowed whole.

Acknowledgements Medical writing and editorial support was provided by Senem Kurtoglu, PhD, of AlphaBioCom, LLC (King of Prussia, PA, USA), and funded by Daiichi Sankyo, Inc. (Parsippany, NJ, USA).

\section{Compliance with Ethical Standards}

Funding The study was funded by Daiichi Sankyo, Inc. (Parsippany, NJ, USA).

Conflict of interest Anil Duggal, Motonori Kidokoro, Tadanobu Takatani, Nicole Shipitofsky, Ling He, George Zhang, and Tarundeep Kakkar are employees of Daiichi Sankyo, Inc.

Open Access This article is distributed under the terms of the Creative Commons Attribution-NonCommercial 4.0 International License (http://creativecommons.org/licenses/by-nc/4.0/), which permits any noncommercial use, distribution, and reproduction in any medium, provided you give appropriate credit to the original author(s) and the source, provide a link to the Creative Commons license, and indicate if changes were made.

\section{References}

1. Savaysa ${ }^{\mathrm{TM}}$ (edoxaban) tablets for oral use. Full prescribing information. Parsippany, NJ: Daiichi Sankyo Inc.; 2015.

2. Matsushima N, et al. Bioavailability and safety of the factor Xa inhibitor edoxaban and the effects of quinidine in healthy subjects. Clin Pharmacol Drug Dev. 2013;2(4):358-66.

3. Mendell $\mathrm{J}$, et al. Effects of food on the pharmacokinetics of edoxaban, an oral direct factor Xa inhibitor, in healthy volunteers. J Clin Pharmacol. 2011;51(5):687-94.
4. Parasrampuria DA, et al. Evaluation of regional gastrointestinal absorption of edoxaban using the enterion capsule. J Clin Pharmacol. 2015;55(11):1286-92.

5. Ogata K, et al. Clinical safety, tolerability, pharmacokinetics, and pharmacodynamics of the novel factor Xa inhibitor edoxaban in healthy volunteers. J Clin Pharmacol. 2010;50(7):743-53.

6. Parasrampuria DA, Truitt KE. Pharmacokinetics and pharmacodynamics of edoxaban, a non-vitamin $\mathrm{K}$ antagonist oral anticoagulant that inhibits clotting factor Xa. Clin Pharmacokinet. 2016;55(6):641-55.

7. Lindgren S, Janzon L. Prevalence of swallowing complaints and clinical findings among 50-79-year-old men and women in an urban population. Dysphagia. 1991;6(4):187-92.

8. Bloem BR, et al. Prevalence of subjective dysphagia in community residents aged over 87. BMJ. 1990;300(6726):721-2.

9. Kelly J, Wright D, Wood J. Medicine administration errors in patients with dysphagia in secondary care: a multi-centre observational study. J Adv Nurs. 2011;67(12):2615-27.

10. Schiele JT, et al. Difficulties swallowing solid oral dosage forms in a general practice population: prevalence, causes, and relationship to dosage forms. Eur J Clin Pharmacol. 2013;69(4):937-48.

11. Cornish P. "Avoid the crush": hazards of medication administration in patients with dysphagia or a feeding tube. CMAJ. 2005;172(7):871-2.

12. Mendell J, Johnson L, Chen S. An open-label, phase 1 study to evaluate the effects of hepatic impairment on edoxaban pharmacokinetics and pharmacodynamics. J Clin Pharmacol. 2015;55(12):1395-405.

13. Moore KT, et al. Rivaroxaban crushed tablet suspension characteristics and relative bioavailability in healthy adults when administered orally or via nasogastric tube. Clin Pharmacol Drug Dev. 2014;3(4):321-7.

14. Song Y, et al. Relative bioavailability of apixaban solution or crushed tablet formulations administered by mouth or nasogastric tube in healthy subjects. Clin Ther. 2015;37(8):1703-12.

15. Song Y, et al. Evaluation of crushed tablet for oral administration and the effect of food on apixaban pharmacokinetics in healthy adults. Clin Ther. 2016;38(7):1674-85.e1. 